(2) Open Access Full Text Article

\title{
Applications of calixarenes in cancer chemotherapy: facts and perspectives
}

This article was published in the following Dove Press journal:

Drug Design, Development and Therapy

2 June 2015

Number of times this article has been viewed

\author{
Ali Yousaf' \\ Shafida Abd Hamid' \\ Noraslinda M Bunnori' \\ AA Ishola ${ }^{2}$ \\ 'Kulliyyah of Science, ${ }^{2}$ Kulliyyah \\ of Medicine, International Islamic \\ University Malaysia, Bandar Indera \\ Mahkota, Malaysia
}

\begin{abstract}
Research on the therapeutic applications of calixarene derivatives is an emerging area of interest. The anticancer activity of various functionalized calixarenes has been reported by several research groups. Due to their superior geometric shape, calixarenes can accommodate drug molecules by forming inclusion complexes. Controlled release of anticancer drugs by calixarenes might help in targeted chemotherapy. This review summarizes the anticancer potential of the calixarenes and their drug loading properties. The potential use of calixarenes in chemoradiotherapy is also highlighted in brief.
\end{abstract}

Keywords: cancer, chemotherapy, calixarenes

\section{Introduction}

Chemotherapy occupies a pivotal position in the treatment of cancer, and its significance in terms of cure and regression of various types of cancer should not be underestimated. ${ }^{1}$ Adjuvant or neoadjuvant and concurrent chemotherapies are usually used along with surgery and radiotherapy. ${ }^{2}$ However, one major drawback that limits the effectiveness of cancer chemotherapy is the non-selective nature of the drugs used. The administrated drugs/agents not only target the cancer cells, but also normal healthy cells. ${ }^{3}$

The ability of anticancer drugs to differentiate between cancerous and healthy cells is generally based on the assumption that tumor cells have a higher growth rate when compared with normal cells. As a result, healthy tissues, such as bone marrow, the gastrointestinal mucosa, hair follicles, and skin are directly affected by a chemotherapeutic regimen, even with preliminary chemotherapy. These side effects lead to various complications during and after treatment., ${ }^{4,5}$

Research on designing anticancer agents is still actively ongoing in the quest to introduce more potent anticancer drugs to the market. However, all available and upcoming anticancer drugs face the same problem of non-selectivity. Therefore, from the last three decades, new trends have been developed for targeted chemotherapy, ie, introduction of nanotechnology, use of cancer biomarkers, and exploration of physical parameters (eg, $\mathrm{pH}$, temperature, light) in the treatment of cancer. ${ }^{6}$ Likewise, surface modification of polymer drugs and nanoparticles is also used as a tool for more effectively targeted chemotherapy. ${ }^{7}$

\section{Biomedical application of supramolecules}

Macromolecules, discovered to have some biomedical applications, behave like drugs, and have shown great potential in drug delivery systems. Among the synthetic macromolecules, crown ether, cyclodextrin, and calixarenes and their derivatives are of great significance. In addition to their unique physicochemical properties, they also serve as hosts that can encapsulate many types of guests. ${ }^{8}$ 
Among the macromolecules, calixarene (Figure 1) is considered to represent the third-generation of host-guest supramolecular chemistry. Calixarene is a cyclic oligomer that can be synthesized by the reaction of phenol with formaldehyde in the presence of a catalytic amount of a strong base or acid. ${ }^{9}$ Calixarenes already have an established place in the pharmaceutical field (Table 1). The flexible nature of the basic moiety and further modification of their basic core and rims make these cyclic oligomers ideal for use as drugs and drug carriers. ${ }^{10,11}$ Calixarene and its derivatives have been reported to have antiviral, antibacterial, antifungal, antitubercular, and anticancer activity. ${ }^{12-14}$ Calix [4]arene, bearing methylenebisphosphonic and hydroxymethylenebisphosphonic acid groups, has an inhibitory effect on protein tyrosine phosphatase 1B, which is involved in insulin and leptin signal transduction, and thus has antidiabetic and antiobesity properties. ${ }^{15}$

\section{Calixarenes as anticancer drugs}

The anticancer activity of calixarene-based compounds has been investigated by several research groups. Baggetto et al ${ }^{16}$ synthesized and studied the effect of calix[4]arene derivatives on various tumor cells (MU2, MU2F, HT1080, SP6.5, 1PC227, Jurkat, MEWO, Hl-60, Huh7, Hep-G2, MEWO, DLM.1) and compared the activity of these compounds with standard anticancer drugs. They discovered that these functionalized calix[4]arene derivatives are potent anticancer agents, particularly in lymphoblastic leukemia and melanoma cell lines. Likewise, Nasuhi Pur and Dilmaghani ${ }^{17}$ synthesized calix[4]arene functionalized with four platinum (II) centers and reported that it was a prospective anticancer agent. When compared with a chemotherapeutic agent, carboplatin, the newly synthesized compound showed better activity against non-small cell lung cancer, hepatocellular cancer, and breast cancer. By using colorimetric cytotoxicity tests, its median inhibitory concentration $\left(\mathrm{IC}_{50}\right)$ in a lung cancer cell line was found to be $2.6 \mu \mathrm{M}$. In another study,

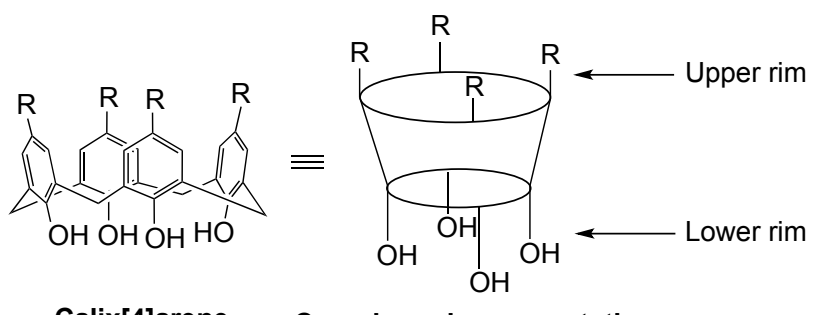

Calix[4]arene

Cup-shaped representation

Figure I Cup-shaped representation of calixarene macrocyle with calix[4]arene as an example. the in vivo effect of glycoconjugates of calix[4]arene in a mouse melanoma model was reported to include a substantial reduction in tumor growth within 2 weeks. ${ }^{18}$

Clinical trial evidence for calixarene-based anticancer agents is still scanty. To date, the US clinical trials database shows only one Phase I study of OTX008, a calixarene-based compound and galectin- 1 inhibitor with potential antiangiogenic and antineoplastic activity. The drug functions through downregulation of a multifunctional carbohydrate binding protein, galectin-1, in patients with advanced solid tumors. The study has been ongoing since 2012, with no results reported as yet.

\section{Mechanisms of action of calixarene- based anticancer agents \\ Enzyme inhibition}

Enzyme inhibition is a common mode of action for some chemotherapeutic drugs. Several calixarenes derivatives have been studied and reported to act as potent enzyme inhibitors. For instance, Cherenok et a ${ }^{19}{ }^{19}$ studied calix[4]arenes coupled with phosphonic, aminophosphonic, and methylenebisphosphonic acid residues and found them to be active inhibitors of some phosphatases such as alkaline phosphatase and tyrosine phosphatase. The same group also reported that hydroxymethylphosphonic acid calixarenes inhibited glutathione-Stransferase, a key enzyme in the xenobiotic detoxification process in cells, thereby contributing toward the multidrug resistance observed in many types of tumors..$^{20}$ Consoli et $\mathrm{al}^{21}$ reported inhibition of DNA replication of a Penicillium digitatum fragment in their study of calix[4]arenes, which were modified with thymine/adenine 2 '-deoxynucleotide moieties via polymerase chain reaction.

\section{Angiogenesis antagonists}

Survival of tumor cells depends on a sufficient supply of nutrients and oxygen, and waste removal via blood vessels. Hence, the presence of new blood vessels within the tumor is essential for their growth. Platelet-derived growth factor (PDGF) plays an important role in angiogenesis by interaction with the PDGF receptor. ${ }^{22}$ The synthesized calixarene derivatives interrupt the interaction of PDGF with its receptor, resulting in prevention of phosphorylation of the receptor, thus acting as antiangiogenic agents. ${ }^{22}$ In an in vitro study using proliferation of endothelial cells, Dings et $\mathrm{a}^{23}$ also revealed that calixarenes possessing tetra-amine, methyl, and diguanidino groups on the lower rim with tert-butyl, isopentyl, isobutyl and propyl groups on the upper rim are potent angiogenesis inhibitors. Later, in vivo studies demonstrated 


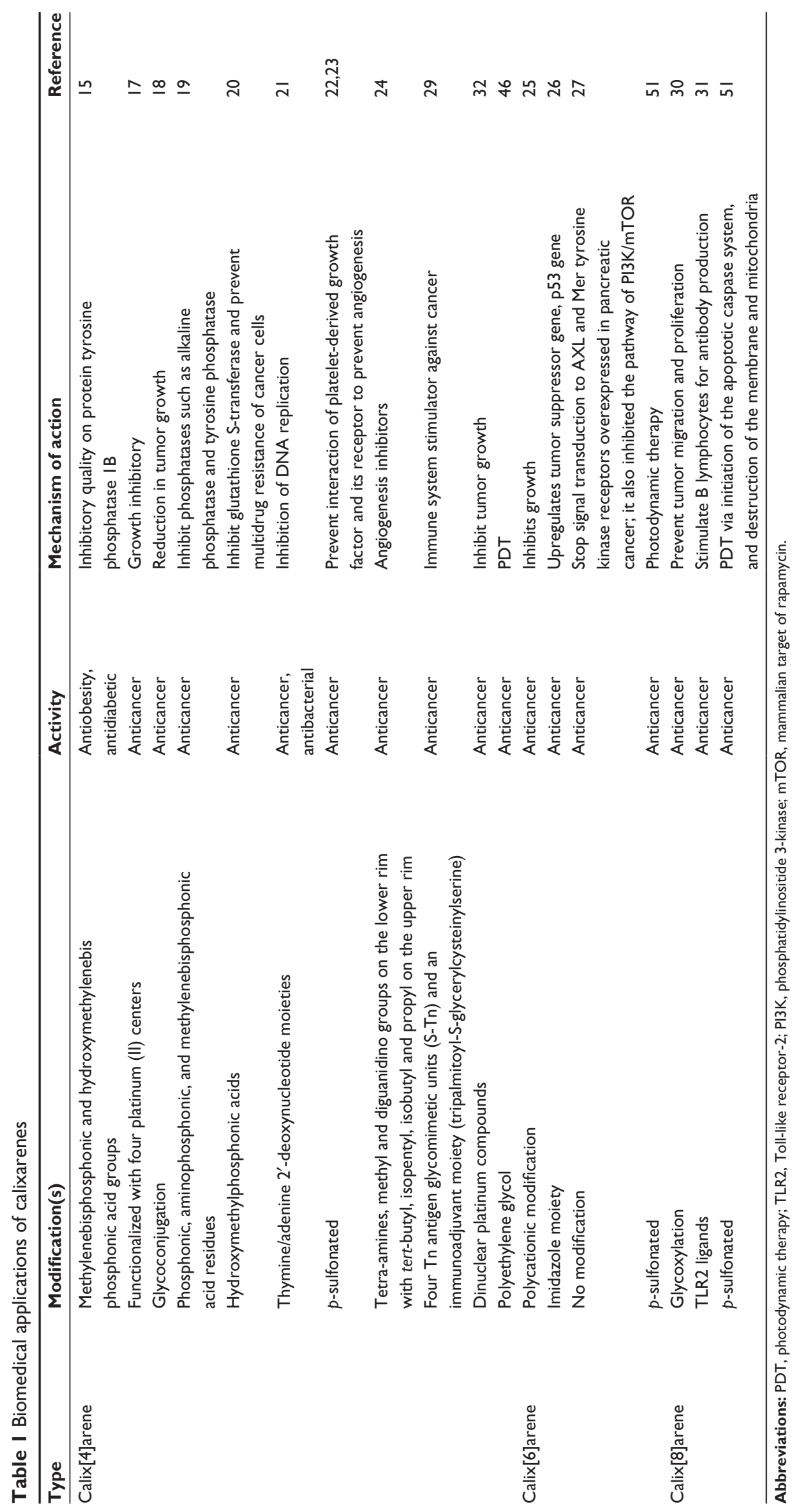


that a polycation-modified member of these compounds had improved efficacy against MA-148 ovarian cancer cells and B16 mouse melanoma cells. ${ }^{23,24}$

\section{Suppression of oncogenes and upregulation of tumor suppressor genes}

An important gene in the etiology of cancer is the tumor suppressor (p53) gene. Li-Fraumeni syndrome, an hereditary disorder, results from mutated p53 tumor suppressor protein. The transcriptional activity of the Li-Fraumeni p53 mutant was found to be improved by imidazolecalix[6]arene moiety through stabilization of oligomer formation. ${ }^{25}$

Pelizzaro-Rocha et $\mathrm{al}^{26}$ investigated the effect and mechanism of calixarenes in a pancreatic carcinoma cell line overexpressing the AXL and Mer tyrosine kinase receptors. Calix[6] arene without any modification was found to be more effective than the commonly administered anticancer drug, 5-fluorouracil. The compound successfully abolished signal transduction of these two receptors and inhibited the phosphatidylinositide 3-kinase/mammalian target of rapamycin pathway. Calix[6] arene was believed to reduce levels of Mer and AXL by stimulating degradation of these two receptors. However, hydrophobic modification of calix[6]arene at the upper rim removed its anticancer potential.

\section{Modulation of innate immunity}

Some anticancer drugs work by stimulating and/or strengthening the ability of the host immune system to combat cancer cells, as achieved by photodynamic therapy (PDT). Likewise, antibody-based chemotherapeutic drugs potently target host immunity components or receptors that enhance proliferation, survival, dedifferentiation, and migration of cancer cells. Examples of such drugs include rituximab $\left(\operatorname{Rituxan}^{\circledR}\right)$, trastuzumab $\left(\right.$ Herceptin $\left.^{\circledR}\right)$, alemtuzumab $\left(\right.$ Campath $\left.^{\circledR}\right)$, bevacizumab $\left(\right.$ Avastin $\left.^{\circledR}\right)$, cetuximab $\left(\right.$ Erbitux $\left.^{\circledR}\right)$, gemtuzumab ozogamicin (Mylotarg ${ }^{\circledR}$ ), calicheamicin, ibritumomab tiuxetan $\left(\right.$ Zevalin $\left.^{\circledR}\right)$, and tositumomab (Bexxar $\left.{ }^{\circledR}\right) \cdot{ }^{27}$ In this respect, calixarenes have also been found useful. A calix[4]arene scaffold linked with four Tn antigen glycomimetic units (S-Tn) and an immunoadjuvant moiety (tripalmitoyl-S-glycerylcysteinylserine) was able to produce better immune-stimulating activity than its corresponding monovalent analogs, thus serving as a novel synthetic cancer vaccine candidate when tested by immunization in mice. ${ }^{28}$ Further investigations showed that glycocalix[8]arenes inhibited migration and proliferation of rat C6 glioma cells in a scratch wound model. ${ }^{29}$
Geraci et $\mathrm{al}^{30}$ also explored the immunotherapeutic anticancer activity of calixarene. They focused on MUC-1 protein, overexpression of which is associated with human epithelial carcinomas. Specifically modified calix[4]arene and calix[8] arene platforms with Toll-like receptor-2 ligands were developed as novel anticancer vaccines. The resulting complex potently stimulated B lymphocytes to produce an antibody specific for MUC-1, denoted as MUC-1 immunoglobulin G antibody.

\section{Calixarenes as anticancer drug carriers: drug-loading capacity}

Due to their distinctive geometry, cup-shaped calixarenes (Table 1) have the ability to accommodate different chemical compounds by forming inclusion complexes through noncovalent bonding, van der Waal's interactions, and hydrogen bonding. Brown et $\mathrm{al}^{31}$ studied the host-guest chemistry of anticancer drug, dinuclear platinum complexes, with parasulfonato-calix[4]arene. Based on spectroscopic results, it was revealed that, in addition to intramolecular and hydrophobic interactions, four intermolecular hydrogen bonds between calix[4]arenes and the dinuclear platinum compounds significantly enhanced the stability of the host-guest complexes. Their anticancer activity was explored in vitro and the complexes were found to be active against A2780 ovarian cancer cells, and particularly against A2780cp70, a cisplatin-resistant subline.

Imatinib is one of the anticancer drugs approved by the US Food and Drug Administration and is known to be a potent tyrosine kinase III inhibitor. Galindo-Murillo et al ${ }^{32}$ investigated the interaction between calixarene derivatives and imatinib. In silico study of these complexes was done through density functional theory (DFT) and molecular dynamics (MD) simulation that explained the controlled delivery of anticancer drug into the tumor cells. ${ }^{33}$ Based on calculation of interaction energies, they found that the cavity size of calixarene and the nature of the attached functional groups played a vital role in the stability of imatinib-calixarene host-guest chemistry. Hydrogen bond donor functional groups were found to be more effective than others. Among the 18 selected calixarene derivatives, they found that calix[6] arene, functionalized with $\mathrm{SO}_{3} \mathrm{H}$ and $\left(\mathrm{CH}_{2}\right)_{2} \mathrm{OH}$ groups at the upper rim, formed more stable complexes with imatinib. ${ }^{32}$ Galindo-Murillo et al also investigated inclusion complexes of an anticancer drug, 3-phenyl-1H-[1] benzofuro[3,2-c]pyrazole (a tyrosine kinase inhibitor) and calix[n]arenes $(n=4,5$, $6,8)$ functionalized with sulfonic acid and ethoxyl groups. They reported that calix[8] arenes and calix[6]arenes, bearing 
an $\mathrm{SO}_{3} \mathrm{H}$ group at the upper rim, formed relatively more stable complexes with 3-phenyl-1H-[1]benzofuro[3,2-c]pyrazole. Again, the large cavity size of these calixarenes and the hydrogen bond donor ability of $\mathrm{SO}_{3} \mathrm{H}$ were considered to be possible reasons for this stability. ${ }^{32}$

\section{Mechanism of drug release}

Optimal conditions are needed for controlled release of drugs from the cavity of a host molecule. One of the mechanisms via which drugs are released from the cavity of calixarene involves a $\mathrm{pH}$-triggered mechanism. The tumor microenvironment has been shown to have $\mathrm{pH}$ values in the range of 5.7-7.8, whereas healthy tissue has a $\mathrm{pH}$ of $7.4 .^{34,35} \mathrm{The} \mathrm{pH}$ difference between normal cells and tumor cells increases further at the subcellular level, and is useful for controlled delivery of anticancer drugs. ${ }^{36}$ The role of $\mathrm{pH}$ in targeted chemotherapy has been clarified further by Vivek et $\mathrm{al}^{37}$ who investigated $\mathrm{pH}$-responsive delivery of oxaliplatin from a chitosan nanocarrier. Oxaliplatin was loaded onto polysaccharide chitosan, and was released from the carrier more rapidly at $\mathrm{pH} 4.5$ than at $\mathrm{pH}$ 7.4. These authors reported inhibition of Bcl-2 and survivin in MCF-7 breast cancer cells by the action of these nanoparticles through $\mathrm{pH}$-triggered mechanism.

Xue et a ${ }^{38}$ similarly reported that the drug-releasing ability of calix[8] arene was pH-dependent. They successfully loaded an antimicrobial drug (ciprofloxacin) onto functionalized water-soluble calix[8]arene and found that the drug was successfully released from the cavity of calix[8]arene via a $\mathrm{pH}$-triggered mechanism. Drug release was found to be $38 \%-42 \%$ with $\mathrm{pH} 7.4$ buffer, $86 \%$ with $\mathrm{pH} 5.0$ buffer, and $82 \%$ with $\mathrm{pH} 8.5$ buffer.

A review by Liu et $\mathrm{al}^{39}$ summarizes the contribution of the different research groups with regard to drug delivery using $\mathrm{pH}$-sensitive based nanosystems. They detailed the role of the $\mathrm{pH}$ difference between normal cells and cancer cells and discussed the mechanism of anticancer drug release and absorption using various organic and inorganic nanosystems. These efforts are helping to overcome the problem of non-selectivity when using chemotherapy for the treatment of cancer.

\section{Photodynamic therapy}

PDT, photoradiation therapy, and photochemotherapy are terms that are used interchangeably to describe a treatment whereby light-sensitive chemicals known as photosensitizers and light radiation are used to combat cancer and other forms of malignancy. ${ }^{40}$ The light is usually in the visible and near-infrared range (400-800 nm). Photosensitizers preferentially remain in tumor cells whereas normal cells eliminate them rapidly. ${ }^{41}$ Therefore, photosensitizers can serve a dual purpose, ie, they serve as both tumor-detecting and tumor-treating agents. ${ }^{42,43}$ The photosensitizer is allowed to distribute around the body and selectively accumulate in cancer cells for few hours or days, depending on the types of photosensitizer. Subsequently, the photosensitizer is activated by irradiation (5-20 minutes) at a wavelength corresponding to the absorbance range of the photosensitizer. ${ }^{40}$ The light is used to excite photosensitizers that triggers non-reversible destruction of tumor cells by stimulating numerous apoptotic pathways, necrosis, or autophagy-mediated cell death. ${ }^{40-42}$ This non-reversible destruction is achieved either by direct interaction of emitted fluorescence energy of excited photosensitizer with cellular biological components (type I) or by transfer of its energy to an innate biological triplet oxygen in order to generate cytotoxic free radical singlet oxygen $\left({ }^{1} \mathrm{O}_{2}\right)$ (type II). ${ }^{41,44,45}$ These generated free radicals can kill cancer cells in various ways, such as by reacting with and destroying vital cell organelles ${ }^{46}$ and by triggering cell-death proteins in the cytoplasm. ${ }^{43}$ Since clinically approved photosensitizers do not accumulate in DNA, the probability of free radical singlet oxygen causing DNA mutation is reduced. ${ }^{40}$ In addition, photosensitizers can destroy blood vessels supplying the tumor, which starves the cancer cells of both nutrients and oxygen until death. ${ }^{43}$ The singlet oxygen generated also helps to overcome the problem of selectivity as it only exerts its cytotoxic action on the tumor cells where it is generated. Due to its very short life span (10-320 nanoseconds), the singlet oxygen cannot diffuse to other surrounding normal cells. ${ }^{40}$ Furthermore, it can also stimulate the immune response to fight cancer cells and this method is advantageous for successful treatment of metastatic cancers. ${ }^{40,42}$

Hematoporphyrin derivatives such as porfimer sodium $\left(\right.$ Photofrin $\left.^{\circledR}\right)$, aminolevulinic acid and its methylesters are the most popular and clinically approved photosensitizers used during PDT. ${ }^{44}$ Preclinical and clinical studies supporting the efficacy of porphyrin photosensitizers for PDT in various precancerous or cancerous growths of the bladder, esophagus, lungs, breast, and skin, as well as non-cancerous diseases have been extensively reviewed by Dougherty et al, ${ }^{41}$ Dougherty, ${ }^{47}$ Brown et al, ${ }^{43}$ and Agostinis et al. ${ }^{40}$ Although convincingly potent, porphyrin photosensitizers have some major drawbacks, in particular, their drug-to-light interval (time between administration of the photosensitizer and light irradiation) during which the patient has to be protected from light is quite long (24-72 hours). ${ }^{42,43}$ Photosensitizers with an absorbance 
wavelength within the near infrared region $(<700 \mathrm{~nm})$ penetrate deeper into the inner organs, which results in better activation of the photosensitizer in those organs and better PDT ${ }^{40}$ However, a photosensitizer such as porfimer sodium absorbs at $630 \mathrm{~nm}$ and has a low molar absorption coefficient $(1,170 \mathrm{M} / \mathrm{cm})$ and thus a large concentration and intensity of light are required for sufficient activation. ${ }^{42}$ In addition, patients experience long-lasting photosensitivity and skin reactions to sunlight after treatment with porphyrin. ${ }^{48}$ Although verteporfin successfully overcomes the long drugto-light interval problem faced by its counterparts because irradiation is applied 15 minutes after its administration, the other aforementioned challenges still remain. ${ }^{42}$ Hence, there is still a need to develop second-generation photosensitizers that overcome a tangible portion of the setbacks faced by the existing photosensitizers.

Calixarenes are also being explored in the search for better photosensitizers in PDT. For example, two synthetic calixarenes ( $p$-sulfonato-calix[6] arene and $p$-sulfonato-calix[8] arene) were found to possess antitumor activity when tested in a K562 myelogenous leukemia cell line using mercury light at $430 \mathrm{~nm} .{ }^{49}$ The mechanism of this cytotoxic effect was discovered through apoptotic activation via caspase system, membrane integrity disruption and mitochondria damage. Another very promising novel study by Cakmak et $\mathrm{al}^{44}$ reported the synthesis of PEGylated bodipycalix(4) arene through a Knoevenagel reaction. Poly(ethylene glycol) (PEG) was added to each bodipyl complex to confer hydrophilic properties on the complex. The resulting compound was reported to absorb light at $725 \mathrm{~nm}$ (near-infrared region) and generate more singlet oxygens which could translate into more cytotoxicity in tumor cells.

\section{Challenges}

In the past, low solubility of calixarenes was considered an obstacle to their application. Incorporation of hydrophilic moieties into the basic core has made them easily soluble in common organic solvents, and the synthesis of water-soluble calixarenes is now common practice. ${ }^{50}$ Different conformations of calixarene can affect its physical and chemical behavior and researchers are able to control this by using various synthetic methods. ${ }^{51}$ Calixarene as a drug, however, does not follow Lipinski's rule of five, especially when bulky groups are introduced at both the upper and lower rims. ${ }^{52}$ Furthermore, the drug carrier potential of calixarene is still not adequate for use in the complex human biosystem. The stability of hostguest chemistry and exact "switch on" release of drug from the cavity of calixarene still needs more investigation.

\section{Conclusion}

Calixarenes possess both drug-like and drug-loading properties. Functionalization at the lower or/and upper rim could enhance their therapeutic value and also solve the problem of their low solubility in water and common organic solvents. The anticancer activity of calixarenes is an emerging area of research which further increases their therapeutical significance. Due to their special geometric shape and flexibility, drugs can easily be incorporated into the cavity of these cyclic oligomers. The release of drugs from the cavity depends on the external factors employed. $\mathrm{pH}$-triggered drug release has been developed by several research groups to some extent, but is still not refined. The narrow difference in $\mathrm{pH}$ range of normal and cancer tissues makes it difficult to specify the target. Radiation-based drug release from the cavity of amphiphilic calixarenes has not been given much consideration. For this purpose, appropriate functionalized calixarenes are being developed and studied. For targeted chemotherapy, research on calixarenes loaded with anticancer drugs and their controlled release upon radiation will provide a new area of interest. Introduction of chemoradiotherapy will minimize the adverse effects of anticancer drugs on normal cells. Thus the administered drugs, though circulating through the whole body, will only be activated/released in the targeted cancer cells through preoptimized radiation. This mechanism seems somewhat different and more sophisticated than that observed in hypoxia-activated prodrugs. Computational study will further help us to understand calixarene-drug stability for auspicious inclusion complexes. Chemotherapy-based radiotherapy is a step toward safer treatment of solid cancers and may be a useful approach to overcome the multidrug-resistant nature of tumor tissue.

In conclusion, the search for new potent anticancer drugs that can only target cancer cells, rather than affecting normal tissues is very much commendable. Calixarene is a highly promising candidate in this regard, and could be modified and appropriately used for targeted chemotherapy. Incorporation of clinically approved active drugs into the basic moiety could enhance the biologically active portion of calixarene.

\section{Acknowledgment}

The authors gratefully acknowledge a grant received from the Ministry of Science, Technology and Innovation (06-0108-SF0147) in support of this research.

\section{Disclosure}

The authors report no conflicts of interest in this work. 


\section{References}

1. Chabner BA, Roberts TG. Chemotherapy and the war on cancer. Nat Rev Cancer. 2005;5(1):65-72.

2. Gilligan TD, Steele GS, Zietman AL, Kantoff PW. Muscle-invasive bladder cancer. In: Kufe DW, Pollock RE, Weichselbaum RR, et al, editors. Holland-Frei Cancer Medicine. 6th ed. Hamilton, ON, Canada: BC Decker; 2003.

3. Agur Z, Arnon R, Schechter B. Reduction of cytotoxicity to normal tissues by new regimens of cell-cycle phase-specific drugs. Math Biosci. 1988;92(1):1-15.

4. Makin G. Principles of chemotherapy. Paediatr Child Health (Oxford). 2014;24(4):161-165.

5. Livshits Z, Rao RB, Smith SW. An approach to chemotherapy-associated toxicity. Emerg Med Clin North Am. 2014;32(1):167-203.

6. Joo WD, Visintin I, Mor G. Targeted cancer therapy - are the days of systemic chemotherapy numbered? Maturitas. 2013;76(4):308-314.

7. Wang Y-C, Liu X-Q, Sun T-M, Xiong M-H, Wang J. Functionalized micelles from block copolymer of polyphosphoester and poly ( $\varepsilon$-caprolactone) for receptor-mediated drug delivery. J Control Release. 2008;128(1):32-40.

8. Takeshita M, Shinkai S. Recent topics on functionalization and recognition ability of calixarenes: the "third host molecule". Bull Chem Soc Jpn. 1995;68(4):1088-1097.

9. Gutsche CD, Dietrich B. Calixarenes revisited. Angew Chem. 2000; 112(1):275-275.

10. Chamseddin C, Jira T. Evaluation of the chromatographic performance of conventional, polar-endcapped and calixarene-bonded stationary phases for the separation of water-soluble vitamins. Chromatographia. 2013;76(9-10):449-457.

11. Schühle DT, Peters JA, Schatz J. Metal binding calixarenes with potential biomimetic and biomedical applications. Coord Chem Rev. 2011; 255(23):2727-2745.

12. Patel DP, Chaudhari BG. Application of supramolecules in drug delivery. Journal of Current Pharmaceutical Research. 2012;9(1):1-5.

13. Mokhtari B, Pourabdollah K. Applications of calixarene nano-baskets in pharmacology. J Incl Phenom Macrocycl Chem. 2012;73(1-4): $1-15$.

14. Rodik RV, Boyko VI, Kalchenko VI. Calixarenes in bio-medical researches. Curr Med Chem. 2009;16(13):1630-1655.

15. Trush VV, Cherenok SO, Tanchuk VY, Kukhar VP, Kalchenko VI, Vovk AI. Calix [4] arene methylenebisphosphonic acids as inhibitors of protein tyrosine phosphatase 1B. Bioorg Med Chem Lett. 2013;23(20): 5619-5623.

16. Baggetto LG, Coleman WA, Lazar AN, Magnard S, Michaud MH. Calixarene derivatives as anticancer agent. US Patent 20100056482 A1. March 4, 2010.

17. Nasuhi Pur F, Dilmaghani KA. Calixplatin: novel potential anticancer agent based on the platinum complex with functionalized calixarene. J Coord Chem. 2014;67(3):440-448.

18. Hulíková K, Grobárová V, Křivohlavá R, Fišerová A. Antitumor activity of $N$-acetyl- $D$-glucosamine-substituted glycoconjugates and combined therapy with keyhole limpet hemocyanin in B16F10 mouse melanoma model. Folia Microbiol. 2010;55(5):528-532.

19. Cherenok SO, Yushchenko OA, Tanchuk VY, et al. Calix [4] arene- $\alpha-$ hydroxyphosphonic acids. Synthesis, stereochemistry, and inhibition of glutathione S-transferase. ARKIVOC. 2012;4:278-298.

20. Cherenok S, Vovk A, Muravyova I, et al. Calix [4] arene $\alpha$ aminophosphonic acids: asymmetric synthesis and enantioselective inhibition of an alkaline phosphatase. Org Lett. 2006;8(4):549-552.

21. Consoli GM, Granata G, Galante E, Di Silvestro I, Salafia L, Geraci C. Synthesis of water-soluble nucleotide-calixarene conjugates and preliminary investigation of their in vitro DNA replication inhibitory activity. Tetrahedron. 2007;63(44):10758-10763.

22. Zhou H, Wang DA, Baldini L, et al. Structure-activity studies on a library of potent calix[4]arene-based PDGF antagonists that inhibit PDGF-stimulated PDGFR tyrosine phosphorylation. Org Biomol Chem. 2006;4(12):2376-2386.
23. Dings RP, Chen X, Hellebrekers DM, et al. Design of nonpeptidic topomimetics of antiangiogenic proteins with antitumor activities. J Natl Cancer Inst. 2006;98(13):932-936.

24. Dings RP, Levine JI, Brown SG, et al. Polycationic calixarene PTX013, a potent cytotoxic agent against tumors and drug resistant cancer. Invest New Drugs. 2013;31(5):1142-1150.

25. Kamada R, Yoshino W, Nomura T, et al. Enhancement of transcriptional activity of mutant $\mathrm{p} 53$ tumor suppressor protein through stabilization of tetramer formation by calix [6] arene derivatives. Bioorg Med Chem Lett. 2010;20(15):4412-4415.

26. Pelizzaro-Rocha KJ, de Jesus MB, Ruela-de-Sousa RR, et al. Calix [6] arene bypasses human pancreatic cancer aggressiveness: downregulation of receptor tyrosine kinases and induction of cell death by reticulum stress and autophagy. BBA Mol Cell Res. 2013;1833(12):2856-2865.

27. Schrama D, Reisfeld RA, Becker JC. Antibody targeted drugs as cancer therapeutics. Nat Rev Drug Discov. 2006;5(2):147-159.

28. Geraci C, Consoli GM, Galante E, Bousquet E, Pappalardo M, Spadaro A. Calix [4] arene decorated with four Tn antigen glycomimetic units and P3CS immunoadjuvant: synthesis, characterization, and anticancer immunological evaluation. Bioconjug Chem. 2008;19(3):751-758.

29. Viola S, Merlo S, Consoli GM, Drago F, Geraci C, Sortino MA. Modulation of C6 glioma cell proliferation by ureido-calix [8] arenes. Pharmacology. 2010;86(3):182-188.

30. Geraci C, Consoli GML, Granata G, et al. First self-adjuvant multicomponent potential vaccine candidates by tethering of four or eight MUC1 antigenic immunodominant PDTRP units on a calixarene platform: synthesis and biological evaluation. Bioconjug Chem. 2013; 24(10):1710-1720.

31. Brown SD, Plumb JA, Johnston BF, Wheate NJ. Folding of dinuclear platinum anticancer complexes within the cavity of parasulphonatocalix[4]arene. Inorg Chim Acta. 2012;393:182-186.

32. Galindo-Murillo R, Olmedo-Romero A, Cruz-Flores E, Petrar P, Kunsagi-Mate S, Barroso-Flores J. Calix[n]arene-based drug carriers: a DFT study of their electronic interactions with a chemotherapeutic agent used against leukemia. Comp Theor Chem. 2014;1035:84-91.

33. Galindo-Murillo R, Sandoval-Salinas ME, Barroso-Flores J. In silico design of monomolecular drug carriers for the tyrosine kinase inhibitor drug imatinib based on calix-and thiacalix [n] arene host molecules: a DFT and molecular dynamics study. J Chem Theory Comput. 2014; 10(2):825-834.

34. Engin K, Leeper D, Cater J, Thistlethwaite A, Tupchong L, McFarlane J. Extracellular $\mathrm{pH}$ distribution in human tumors. Int J Hyperthermia. 1995;11(2):211-216.

35. Stubbs M, McSheehy PM, Griffiths JR, Bashford CL. Causes and consequences of tumor acidity and implications for treatment. Mol Med Today. 2000;6(1):15-19.

36. Lee ES, Oh KT, Kim D, Youn YS, Bae YH. Tumor pH-responsive flower-like micelles of poly(L-lactic acid)- $b$-poly (ethylene glycol)b-poly (L-histidine). J Control Release. 2007;123(1):19-26.

37. Vivek R, Thangam R, Nipunbabu V, Ponraj T, Kannan S. Oxaliplatinchitosan nanoparticles induced intrinsic apoptotic signaling pathway: a "smart" drug delivery system to breast cancer cell therapy. Int J Biol Macromol. 2014;65:289-297.

38. Xue Y, Guan Y, Zheng A, Xiao H. Amphoteric calix[8]arene-based complex for $\mathrm{pH}$-triggered drug delivery. Colloids Surf B Biointerfaces. 2013;101:55-60.

39. Liu J, Huang Y, Kumar A, et al. pH-sensitive nano-systems for drug delivery in cancer therapy. Biotechnol Adv. 2013;32(4):693-710.

40. Agostinis P, Berg K, Cengel KA, et al. Photodynamic therapy of cancer: an update. CA Cancer J Clin. 2011;61(4):250-281.

41. Dougherty TJ, Gomer CJ, Henderson BW, et al. Photodynamic therapy. J Natl Cancer Inst. 1998;90(12):889-905.

42. Dolmans DE, Fukumura D, Jain RK. Photodynamic therapy for cancer. Nat Rev Cancer. 2003;3(5):380-387.

43. Brown SB, Brown EA, Walker I. The present and future role of photodynamic therapy in cancer treatment. Lancet Oncol. 2004;5(8): 497-508. 
44. Cakmak Y, Nalbantoglu T, Durgut T, Akkaya EU. PEGylated calix [4] arene as a carrier for a Bodipy-based photosensitizer. Tetrahedron Lett. 2014;55(2):538-540.

45. Pass HI. Photodynamic therapy in oncology: mechanisms and clinical use. J Natl Cancer Inst. 1993;85(6):443-456.

46. Piette J, Volanti C, Vantieghem A, Matroule J-Y, Habraken Y, Agostinis P. Cell death and growth arrest in response to photodynamic therapy with membrane-bound photosensitizers. Biochem Pharmacol. 2003;66(8): 1651-1659.

47. Dougherty TJ. An update on photodynamic therapy applications. J Clin Laser Med Surg. 2002;20(1):3-7.

48. Grant W, MacRobert A, Bown S, Hopper C, Speight P. Photodynamic therapy of oral cancer: photosensitisation with systemic aminolaevulinic acid. Lancet. 1993;342(8864):147-148.
49. Neagu M, Ion R-M, Manda G, Constantin C, Radu E, Cristu Z. Antitumoral effect of calixarenes in experimental photodynamic therapy with K562 tumor cell line. Rom J Biochem. 2010;47(1):17-35.

50. Ryu E-H, Zhao Y. Efficient synthesis of water-soluble calixarenes using click chemistry. Org Lett. 2005;7(6):1035-1037.

51. Gutsche CD, Bauer LJ. Calixarenes. 13. The conformational properties of calix[4]arenes, calix[6]arenes, calix[8]arenes, and oxacalixarenes. J Am Chem Soc. 1985;107(21):6052-6059.

52. Bhal SK, Kassam K, Peirson IG, Pearl GM. The Rule of Five revisited: applying $\log \mathrm{D}$ in place of $\log \mathrm{P}$ in drug-likeness filters. Mol Pharm. 2007;4(4):556-560.

\section{Publish your work in this journal}

Drug Design, Development and Therapy is an international, peerreviewed open-access journal that spans the spectrum of drug design and development through to clinical applications. Clinical outcomes, patient safety, and programs for the development and effective, safe, and sustained use of medicines are a feature of the journal, which has also been accepted for indexing on PubMed Central. The manuscript management system is completely online and includes a very quick and fair peer-review system, which is all easy to use. Visit http://www.dovepress.com/testimonials.php to read real quotes from published authors.

Submit your manuscript here: http://www.dovepress.com/drug-design-development-and-therapy-journal 